\title{
GET NOTICED AND STAY RELEVANT TO WEB USERS!
}

\author{
Tania Grové (RAU) \& Essias Bootha (New Dawn Technology)
}

The study is based on the question why people visit some websites numerous times and other web sites only once. The problem for companies that decide to make use of the web as a marketing tool is not just how to get connected to the web, but getting noticed and staying relevant to its clients and potential clients. The main objective of this study was thus to investigate what influence people to return to a web site and what are their requirements from web sites. These answers will show how companies can ensure that people notice their websites, how they can be influenced to connect to their web sites and how these companies can retain the people connecting to their web sites as customers with diverse needs. This information will enable companies to develop and customise applicable strategies for their web sites to satisfy the needs of their target markets. The analysis of the responses showed that most of the respondents are not using the web to purchase items; that customer preferences vary and that the web is more effective than traditional media on certain variables.

Keywords: web presence, return visits to web sites, characteristics of web sites

\section{INTRODUCTION}

The community is bombarded by newspapers, television, magazines, radio and the web by words such as the web, World Wide Web, www, cyberspace and Internet. Internet, the web, the net, cyberspace and www whilst used frequently are to some extend still mysterious words that are fast becoming part of everybody's vocabulary but which are still not clearly understood by most companies and members of the public (Landman 2000).

As the web's popularity grew, more and more consumers got connected to the web, companies started to identify the web as an excellent marketing opportunity and developed their own web sites. A lot of research has been done providing results about success stories of web sites such as the Amazon web site. Likewise, there are many guidelines or tips available on how to develop web sites. With all these positive messages companies tend to overlook their peers that ventured onto the web and found that the expected successes turned out to be disasters. A large number of companies found that marketing on the web was not an easy exercise and after a while were either forced to stop their web efforts or quests (Brigman 1996). The impact of web site failures are millions of dollars in lost revenue, lost customers, negative publicity and immeasurable damage to the image of the company (Hsu 2000). A mistake many companies make is that they assume that their market is similar to those not connected to the web. Companies tend to overlook what consumers require from the web site. Companies do not understand the needs of their markets on the web. Any company that attempts to make use of the web as a marketing tool must know and understand its target market on the web and their expectations from the web site.

Developing a web site is much more than just copying the company's brochure onto the web. Companies need to understand how to make use of the web. Attention must be given to 
aspects such as proper interaction with customers, adherence to the rules of web sites, design issues, the promotion of the web sites, and choosing the most effective domain name (Aspinal 1997). When companies want to do marketing on the web they must know who the target market is, what they require from web sites, why they would return to web sites, and how they got to know about web sites. The purpose of the study was thus to determine how companies can get noticed on the web by consumers and how to stay relevant to their customers.

\section{LITERATURE OVERVIEW}

The web is a large interconnected network of computer networks linking people and computers all over the world via telephone lines, satellites and other telecommunication systems. The web provides a lot of new challenges and opportunities for companies with regards to marketing. There are several characteristics of the web that makes the web an ideal marketing medium (Allen 1998; Bonfield 2000; Frankel 1999; Garratt 1998; Gibson 1999; Harden et al. 1999; Ling 2000; McNamee 1995; Schmidt 2000 and Wiese 1999).

The web is the first many-to-many medium. The reason for this is that there is no broadcast medium to control access, all it takes is a little technology and one gets connected to the web.

- The web breaks the barriers of traditional press, radio and television advertising. It combines the technologies of all three and opens a fourth door, namely interactivity. On the web a company's customers are active participants. A visitor can communicate; fill in surveys, place orders for products and issue payments for products immediately, without getting off his/her chair. Interactivity can be the key component of a marketing or promotional web site and can be used to attract consumers, collect information about the consumers and promote client loyalty.

- When a company's doors are locked and the switchboard has closed for the night, business comes to an end, aside from the arrival of faxes and answering machine messages. This means that the potential customer who needs information or assistance is shut out. The web enables a company to have a twenty-four hour sales representative and as such become globally competitive.

- One of the best characteristics of the web is that the web is very graphical. Companies can make use of various graphical presentations to get their message across to consumers to the web site. This helps the marketers to display their message in an easier and much more comprehensible, enhanced and graphical format. The web can assist the company to make a positive first impression on consumers with regards to the company and its products. Its customers will perceive a company that uses sensational features as a company that takes the web site seriously. These features can go a long way to retain customers and entice them to keep on visiting the site.

- On-line marketers avoid the expense of maintaining a store and the accompanying cost of rent, insurance and utilities. They can produce digital catalogues for much less that the 
cost of printing and mailing paper catalogues. Reaching the web user is easy and highly cost-effective - the cost per viewing ranging from 12 to20c depending on the type of placement.

- The web also conquers time and space. Virtually any amount of information can be sent almost anywhere in the world in seconds. Whether or not a user's working partner is in China or Cairo becomes largely irrelevant. The web-user can interact in real time with a colleague and they can exchange information more easily than to pass a document to someone in the next office. The cost of duplicating and distributing information has been reduced to almost zero.

- On-line marketers can determine how many people visited their website and how many stopped at particular places on the site. This information enables marketers to improve their market offerings and advertisements. The web allows media planners to account for every individual who ever looked at the advertisement or responded to it by clicking on it.

- One-to-one marketing can assist in motivating consumers to return to a company's web site, it can create a community of loyal customers and can reduce the cost of customer service. The power of the web enables a company to create a one-to-one relationship with each individual who visits the web site. This enhances the impact of the web site since consumers want to be recognised and treated as individuals; it improves the success of the web site; and increases the return on their web marketing investment.

- The web overcomes many of the traditional problems associated with service marketing, such as consistency, standardization and quality control. For companies, such as banks, legal aids and educational institutions, the web is an interactive medium that combines the best of mass production and customisation.

Consumers need to be attracted to web sites through the service and information that the web site provides as well as the design of an ideal image and/or perception of the web site. On-line marketers must determine the consumers' information needs and must provide the relevant information and features in order to encourage interactivity and loyalty. Site layout is also very important since the layout of the site will determine how the target market experiences the site. Companies must realize that web users are discerning consumers, and as such, they require a greater degree of encouragement to make use of a site. Web users also tend to fall into two categories - they either tend to get bored quickly or they are busy people (Gibson 1999 and Graham 1997).

Therefore, it is essential that the web pages must be fast loading, and websites must be managed in terms of quality, reliability, frequency of updates, and download speeds. Quality is communicated via the visual impact of the site. The site must be frequently updated otherwise visitors are unlikely to return. Consumers will loose interest if the content is not valid anymore (Graham 1997).

There are several reasons why a consumer visits or returns to a website. The first reason is curiosity. If it is a large site and there is too much to see in an one online session, consumers will come back. The information and activities must not be confusing, but the consumer 
should feel that there is a value to obtain on just about every page and that this as a valuable site worth returning to for more exploration. The second reason is item turnover. Companies must provide at least something that changes frequently or even every time someone visits. This may be a what-is-new feature, but often it can be something as simple as a daily aphorism or coverage of a current event broadly related to the applicable industry. It can also be something like a random URL or a new audio file every time someone visits the site. All web sites are transient to some degree, with new material being added and old material moved or eliminated. As a general rule, a marketing orientated site should be prepared to update pages on a daily basis, with a goal of updating the entire site every few months. It is important to remember that one of the primary features bringing back visitors to web sites is new material. Therefore, companies must invest substantially in creating new content constantly (Graham 1997 and Gibson 1994).

Another reason why a consumer will return to a web site is that he/she must see the web as an indispensable resource tool. A web page can offer links to existing databases, collections of webs and web guides, searching tools, or a list of available images and files. While any such links are worthwhile, the site is more likely to bring people back if the collection of links is very extensive and/or high in quality. The links can be on any subject, such as contests, give-aways, conferences, etc. but it makes sense to have them relate in some way to the company's business. Another option is to provide an as- the-expert feature that will allow web users to submit or e-mail questions and the expert can then go and place the answers on the page (Gibson 1999).

It is also important that the web site must be easy to navigate. The visitor must find the web site easy to use. Links must be present either at the top and bottom or a navigation bar on the right or left of the web page. The navigation buttons must be in the same place on each page as not to confuse the visitor. Additionally, the web site needs a consistent theme to ensure that the consumers know they are still on the same site otherwise they will lose interest. Consumers must also be able to easily read the web site material. For example, there must be a high contrast between the background and the text colours. When using multimedia such as sound and video, companies need to make sure that these additions do not cause the web site taking too long to download. Finally, companies must ensure that web pages do not have script and grammatical errors, that the web site must work as it is suppose to, that the web site is complete, that the essential information be presented on the first screen that consumers will see, and that all links on their web sites do exist (Bristol, http://bristol-web.co.uk; Graham 1997; Kitching 1999; http://www.tka.co.uk/magic/ archive/ archv11. htm\#Q3).

\section{METHODOLOGY USED IN RESEARCH}

The elements of this research lend itself to be classified as descriptive research where the focus was to obtain accurate description information of the variables that were investigated. The universe of the study represented the South African web users ( \pm 2 million consumers). The sample size was primarily determined by financial limitations and timeframe involved. A total of 1500 suitable consumers had been identified. The research sample had been designed by making use of non-probability sampling, that is, the sampling was non-random 
and subject, meaning that each member of the sample did not have a known nonzero chance of being included. The email addresses of consumers have been obtained from various sources such as business cards, the web and e-mail directories.

The assumption had been made that all the respondents involved with the research were familiar with the web and already surfed the web and interacted with numerous websites. Complex technical details relevant to the web and the development of web sites were not dwelled upon. The study's main focus was from a business perspective and not from a technical information technology perspective. The research concentrated on marketing problems related to the web.

The survey method (e-mail survey) was identified as the most suitable method for data collection. The contact with the respondents had been of an impersonal nature by means of a self-administered questionnaire. The questionnaire was designed in such a way that it solicited the sample members to take part in the study and to complete the questionnaire in a valid and complete manner. The interactive questionnaire was made available to participants on the web site created for this purpose as well as a Microsoft Word document. The distribution of the questionnaire and the link to the web site was done via email. An explanation about the study and its purpose was included on the web site and in the document. All the responses received were stored automatically on a database that allowed for retrieval of the data once the study was completed. An electronic copy of the questionnaire was also made available that made provision for consumers that were uncomfortable completing it on a web site. As an incentive, participants that provided their email addresses had a chance of winning an R150.00 gift voucher at a well-known shopping centre.

The statistical processing had been done by means of a computer software package (Statistical Package for Social Sciences). The results were presented in frequency tables based on the results analysed. Most of the questions required the respondents to provide a rating between 1 and 5, where 1 represented the most negative rating and 5 the most positive rating. In order to facilitate the presentation and the understanding of the results, the results had been converted to be presented in a 3 point scale ( 1 and 2 combined to represent a negative rating; 3 as neutral; and 4 and 5 combined to represent a positive rating). It was important to determine if a variance between consumer feature preferences and profile variables does exist. Since there were only three levels used, the Pearson's Chisquare $\left(\chi^{2}\right)$ were used. The variables for the chi-square were done at statistical levels of 0.05 for the purpose of this study.

\section{RESEARCH RESULTS}

Of the 1500 questionnaires that had been sent out, 187 valid responses had been returned, representing a response rate of $13.4 \%$. The gathered data focus on the importance of the surfing habits of respondents, influences to visit and return to web sites and the importance certain media characteristics have to respondents. The profile of the respondents is summarized in table 1. 
TABLE 1: PROFILE OF RESPONDENTS

\begin{tabular}{|llc|}
\hline Age & 25 and younger & $19.8 \%$ \\
& $26-30$ & $41.2 \%$ \\
& $31-40$ & $29.4 \%$ \\
& Older than 40 & $9.6 \%$ \\
\hline Gender & Male & $62.0 \%$ \\
& Female & $38.0 \%$ \\
\hline Occupation & Student & $14.4 \%$ \\
& Admin & $13.8 \%$ \\
& Professional & $71.1 \%$ \\
& Retired & $0.7 \%$ \\
\hline Education & Matric and less & $14.4 \%$ \\
& Post graduate qualification & $85.6 \%$ \\
\hline Period utilizing the web & One year and less & $12.8 \%$ \\
& More than one year & $87.2 \%$ \\
\hline Frequency utilising the web & More than once a day & $78.1 \%$ \\
& Only once a day & $11.2 \%$ \\
& Only 1-2 times every two weeks & $5.9 \%$ \\
& Only 1-2 times every month & $4.8 \%$ \\
\hline
\end{tabular}

Respondents were asked to rate the level of importance the web have to them based on a number of predetermined purposes (utilities) that were represented to them (table 2). Table 2 shows that the majority of the respondents consider the web important for business related e-mail and interacting with companies while less than $20 \%$ of the respondents do not consider the web important for the purchasing of goods, game playing, taking part in auctions, and share trading.

TABLE 2: IMPORTANCE OF THE WEB

\begin{tabular}{|lccc|}
\hline PURPOSE / UTILIZATION & $\begin{array}{c}\text { Not important } \\
\%\end{array}$ & $\begin{array}{c}\text { Neutral } \\
\%\end{array}$ & $\begin{array}{c}\text { Very } \\
\text { important } \\
\%\end{array}$ \\
\hline Business related e-mail & 10.7 & 16.0 & 73.3 \\
Interacting with companies & 18.2 & 18.2 & 63.6 \\
Research & 46.0 & 12.3 & 41.7 \\
Accessing information & 49.2 & 15.5 & 35.3 \\
Personal e-mail & 43.9 & 25.1 & 31.0 \\
Download of software & 47.1 & 15.1 & 27.8 \\
Download of graphics & 60.4 & 13.4 & 26.2 \\
Hobbies & 38.0 & 36.9 & 25.1 \\
Adult entertainment & 72.2 & 6.4 & 21.4 \\
Purchasing of goods & 35.8 & 45.5 & 18.7 \\
Game playing & 74.3 & 9.1 & 16.6 \\
Taking part in auctions & 51.3 & 35.8 & 12.8 \\
Share trading & 33.7 & 54.5 & 11.8 \\
\hline
\end{tabular}


Respondents were asked to indicate the level of importance that the different web sites have to them (table 3). According to the results, the dynamic content based web sits are most valued by the respondents, while ecommerce focussed sites are of least importance to the respondents. It can be deducted that e-commerce has not been accepted by the respondents as a medium of doing business.

TABLE 3: IMPORTANCE OF THE TYPE OF WEB SITES

\begin{tabular}{|lccc|}
\hline TYPE OF WEB SITE & $\begin{array}{c}\text { Not important } \\
\%\end{array}$ & $\begin{array}{c}\text { Neutral } \\
\%\end{array}$ & $\begin{array}{c}\text { Very } \\
\text { important } \\
\%\end{array}$ \\
\hline Dynamic content based sites & 25.1 & 27.3 & 47.6 \\
Interactive entertainment focused web sites & 46.0 & 13.4 & 40.6 \\
General interactive web sites & 41.7 & 28.3 & 29.9 \\
E-Commerce focused sites & 59.9 & 17.1 & 23.0 \\
Static content based sites & 33.7 & 45.5 & 20.9 \\
\hline
\end{tabular}

Respondents were asked to indicate to what extend certain variables such as situations or other media influence them to visit websites for the first time (table 4). The order of importance of the different variables that are most frequently used to visit web sites for the first time is shown in table 4. The search for product information is considered as the most important variable which shows the importance of having content of interest and of value on web sites as well as to register sites and keywords on search engines. The high ranking of posters is a clear indication of the importance to put the URL's of the web sites on marketing material in order to make it easy for the web consumer to access web sites. Billboards were ranked by respondents as one of the aspects that rarely influence them to visit web sites. This information is valuable in illustrating the importance of choosing the correct advertising engines and methods to attract and retain consumers to web sites.

TABLE 4: IMPORTANCE OF VARIABLES TO INFLUENCE RESPONDENTS TO VISIT WEB SITES

\begin{tabular}{|cl|}
\hline 1 & Product information \\
2 & Newspapers \\
3 & Posters \\
4 & Word of mouth \\
5 & Business cards \\
6 & E-mail invitations \\
7 & Search engines \\
8 & Magazines \\
9 & Television \\
10 & Links on other websites \\
11 & Promotion of company \\
12 & Flyers / pamphlets \\
13 & Company brand \\
14 & Radio \\
15 & Billboards \\
\hline
\end{tabular}


Respondents were asked to indicate the importance they attach to some website features in influencing them to return to web sites (table 5). Indications are that respondents consider user friendliness, functionality, completeness of the site, error free, and easy navigation amongst other features as more important in influencing them to return to web sites. Features such as company information, sense of belonging, competitions, multimedia, and up-to-date content are of lesser importance to the respondents. This information will enable companies to determine what actions they must take to ensure return visits to their web sites. However, companies must be careful not to consider the more important features as the only features they must adhere to. There are numerous ways to enhance web sites and attract consumers to web sites.

TABLE 5: IMPORTANCE OF FEATURES OF WEB SITES TO INFLUENCE RESPONDENTS TO RETURN TO WEB SITES

\begin{tabular}{|lccc|}
\hline WEB FEATURE & $\begin{array}{c}\text { Not important } \\
\%\end{array}$ & $\begin{array}{c}\text { Neutral } \\
\%\end{array}$ & $\begin{array}{c}\text { Very } \\
\text { important } \\
\%\end{array}$ \\
\hline User friendliness & 6.4 & 7.0 & 86.6 \\
Functionality & 5.3 & 15.5 & 79.1 \\
Completeness of site & 5.9 & 16.0 & 78.1 \\
Error-free & 10.2 & 15.5 & 74.3 \\
Easy navigation & 5.9 & 23.0 & 71.1 \\
Interacting with other people & 25.1 & 9.6 & 65.2 \\
Latest new of interest & 8.0 & 30.5 & 61.5 \\
Entertainment & 23.0 & 16.6 & 60.4 \\
Research & 28.9 & 22.5 & 48.7 \\
Ordering and purchasing goods & 28.9 & 24.6 & 46.5 \\
Product information & 34.2 & 21.4 & 44.4 \\
Graphics & 28.9 & 28.9 & 42.2 \\
Fast download time & 54.0 & 7.5 & 38.5 \\
Layout of site & 20.9 & 43.9 & 35.5 \\
Curiosity of what is new & 34.8 & 30.5 & 34.8 \\
Appearance & 44.9 & 21.9 & 33.2 \\
Downloadable programs & 53.5 & 15.0 & 31.6 \\
Games & 39.0 & 29.9 & 31.0 \\
Content up to date & 57.2 & 11.8 & 31.0 \\
Interactivity & 38.0 & 31.6 & 30.5 \\
Readability of content & 25.7 & 44.4 & 29.9 \\
On-Line help availability & 14.4 & 57.8 & 27.8 \\
Feedback from company & 27.8 & 48.7 & 23.5 \\
Company information & 43.9 & 36.4 & 19.8 \\
Feel sense of belonging & 72.2 & 10.7 & 17.7 \\
Competitions & 39.6 & 44.4 & 16.0 \\
Multimedia & 50.8 & 35.8 & 13.4 \\
\hline
\end{tabular}


The relationship between the various levels of importance (table 5) and the profile of the respondents (table 1) were determined in order to indicate whether a relationship between preference and profile does exist (table 6). Table 6 shows that there are significant statistical differences at the $5 \%$ level of significance between the level of importance (respondents attached to some website features in influencing them to return to web sites) and some of the profile variables. It can thus be concluded that preferences will vary from consumer to consumer and that companies should find the feature or combination of features that best match their market. It implicates that web-based markets should also be segmented to determine the profile and homogeneous needs of the different segments.

TABLE 6: SUMMARY OF ANALYSIS OF VARIANCE BETWEEN THE IMPORTANCE OF EATURES AND THE PROFILE OF RESPONDENTS

\begin{tabular}{|c|c|c|c|c|c|}
\hline WEB FEATURE & Gender & Education & $\begin{array}{c}\text { Period } \\
\text { used }\end{array}$ & Age & $\begin{array}{l}\text { Frequency } \\
\text { utilizing } \\
\text { the web }\end{array}$ \\
\hline User friendliness & 0.061 & 0.099 & 0.521 & 0.092 & 0.052 \\
\hline Functionality & 0.031 & 0.082 & 0.409 & 0.312 & 0.042 \\
\hline Completeness of site & 0.935 & 0.009 & 0.041 & 0.289 & 0.011 \\
\hline Error-free & 0.725 & 0.031 & 0.742 & 0.792 & 0.050 \\
\hline Easy navigation & 0.543 & 0.179 & 0.812 & 0.543 & 0.004 \\
\hline Interacting with other people & 0.049 & 0,072 & 0.197 & 0.044 & 0.214 \\
\hline Latest news of interest & 0.612 & 0.095 & 0.002 & 0.012 & 0.190 \\
\hline Entertainment & 0.002 & 0.128 & 0.166 & 0.047 & 0.487 \\
\hline Research & 0.005 & 0.021 & 0.239 & 0.734 & 0.049 \\
\hline $\begin{array}{l}\text { Ordering and purchasing } \\
\text { goods }\end{array}$ & 0.075 & 0.254 & 0.041 & 0.087 & 0.053 \\
\hline Product information & 0.598 & 0.019 & 0.092 & 0.183 & 0.041 \\
\hline Graphics & 0.012 & 0.199 & 0.653 & 0.654 & 0.059 \\
\hline Fast download time & 0.559 & 0.911 & 0.008 & 0.092 & 0.025 \\
\hline Layout of site & 0.842 & 0.623 & 0.016 & 0.482 & 0.008 \\
\hline Curiosity of what is new & 0.613 & 0.029 & 0.290 & 0.763 & 0.289 \\
\hline Appearance & 0.005 & 0.621 & 0.693 & 0.188 & 0.753 \\
\hline Downloadable programs & 0.599 & 0.925 & 0.022 & 0.542 & 0.109 \\
\hline Games & 0.044 & 0.072 & 0.734 & 0.008 & 0.432 \\
\hline Content up to date & 0.812 & 0.823 & 0.045 & 0.189 & 0.038 \\
\hline Interactivity & 0.742 & 0.191 & 0.611 & 0.523 & 0.390 \\
\hline Readability of content & 0.042 & 0.253 & 0.321 & 0.062 & 0.743 \\
\hline On-Line help availability & 0.882 & 0.000 & 0.049 & 0.491 & 0.029 \\
\hline Feedback from company & 0.643 & 0.643 & 0.190 & 0.293 & 0.689 \\
\hline Company information & 0.772 & 0.001 & 0.098 & 0.498 & 0.382 \\
\hline Feel sense of belonging & 0.542 & 0.358 & 0.257 & 0.078 & 0.413 \\
\hline Competitions & 0.009 & 0.181 & 0.039 & 0.094 & 0.743 \\
\hline Multimedia & 0.823 & 0.082 & 0.021 & 0.289 & 0.918 \\
\hline
\end{tabular}


Respondents also had to rate the level of importance that the web consumer assign to certain web activities (table 7). Respondents indicated that they consider newsgroups and chat rooms as more important while discussion lists are of the least importance to respondents.

TABLE 7: IMPORTANCE OF WEB ACTIVITIES

\begin{tabular}{|lccc|}
\hline WEB ACTIVITY & $\begin{array}{c}\text { Not important } \\
\%\end{array}$ & $\begin{array}{c}\text { Neutral } \\
\%\end{array}$ & $\begin{array}{c}\text { Very important } \\
\%\end{array}$ \\
\hline Newsgroups & 17.1 & 13.4 & 69.5 \\
Chat rooms & 33.2 & 6.4 & 60.4 \\
F T P & 48.1 & 5.9 & 46.0 \\
Telnet & 27.1 & 33.2 & 39.6 \\
Discussion lists & 78.1 & 8.6 & 13.4 \\
Gopher & 64.2 & 26.2 & 9.6 \\
\hline
\end{tabular}

Respondents were asked to indicate the importance of the various criteria they associate with certain media or methods when prompted to visit a web site by these media. The percentage of respondents that consider the different criteria as very important for the respective media are shown in table 8 . The results are relatively evenly spread and it can be deducted that respondents do not consider any particular media as being more important in influencing them to visit web sites. The reason for the even spread might be that respondents prefer to experience web sites for themselves rather than taking advise from other media.

TABLE 8: IMPORTANCE OF CRITERIA REGARDING CERTAIN MEDIA

\begin{tabular}{|c|c|c|c|c|c|c|c|}
\hline \multirow[b]{2}{*}{ MEDIA } & \multicolumn{7}{|c|}{ DIFFERENT CRITERIA } \\
\hline & $\begin{array}{c}\text { Trust- } \\
\text { worthiness } \\
\%\end{array}$ & $\begin{array}{l}\text { Visibility } \\
\quad \%\end{array}$ & $\begin{array}{l}\text { Media } \\
\text { opinion } \\
\%\end{array}$ & $\begin{array}{c}\text { Accessibility } \\
\text { lavailability } \\
\%\end{array}$ & $\begin{array}{c}\text { Professional } \\
\text { opinion } \\
\%\end{array}$ & $\begin{array}{c}\text { Attractive } \\
\text {-ness } \\
\%\end{array}$ & $\begin{array}{c}\text { Repetitive } \\
\text { ness } \\
\%\end{array}$ \\
\hline Billboards & 24.1 & 32.6 & 24.1 & 24.6 & 21.4 & 33.7 & 44.4 \\
\hline Business cards & 28.3 & 25.7 & $\mathrm{n} / \mathrm{a}$ & 25.7 & $\mathrm{n} / \mathrm{a}$ & 39.0 & 16.6 \\
\hline Company brand & 21.9 & 40.1 & $\mathrm{n} / \mathrm{a}$ & 16.0 & $\mathrm{n} / \mathrm{a}$ & 43.9 & 23.5 \\
\hline E-mail invitations & 48.7 & 28.9 & 33.2 & 39.6 & 24.6 & 31.0 & 10.2 \\
\hline Flyers / pamphlets & 19.8 & 21.4 & 22.5 & 21.4 & 27.8 & 31.0 & 9.6 \\
\hline $\begin{array}{l}\text { Links on other web } \\
\text { sites }\end{array}$ & 41.2 & $\mathrm{n} / \mathrm{a}$ & 41.2 & 46.0 & $\mathrm{n} / \mathrm{a}$ & 41.2 & 34.8 \\
\hline Magazines & 19.8 & 44.4 & 38.5 & 21.9 & 34.8 & $\mathrm{n} / \mathrm{a}$ & 26.7 \\
\hline Newspapers & 52.9 & 33.7 & 37.4 & 51.9 & 31.6 & $\mathrm{n} / \mathrm{a}$ & 23.0 \\
\hline Posters & 49.2 & 30.5 & $\mathrm{n} / \mathrm{a}$ & 43.9 & 28.3 & 33.2 & 16.0 \\
\hline Promotion of company & 46.0 & 43.9 & 49.2 & 43.9 & $\mathrm{n} / \mathrm{a}$ & 52.4 & 27.8 \\
\hline Radio & 19.8 & 36.4 & 38.5 & 22.5 & 35.8 & $\mathrm{n} / \mathrm{a}$ & 27.3 \\
\hline Search engines & 3.5 & 58.3 & $\mathrm{n} / \mathrm{a}$ & 36.4 & 50.8 & $\mathrm{n} / \mathrm{a}$ & $\mathrm{n} / \mathrm{a}$ \\
\hline Television & 18.7 & 43.3 & 25.1 & 25.1 & 38.5 & $\mathrm{n} / \mathrm{a}$ & 27.3 \\
\hline Word-of-mouth & 28.9 & $\mathrm{n} / \mathrm{a}$ & 62.6 & 33.2 & 33.2 & $\mathrm{n} / \mathrm{a}$ & 44.7 \\
\hline
\end{tabular}


Respondents also had to compare the web to other media on certain criteria (benefits or effectiveness). The results of the respondents regarding the effectiveness of the web compared to different media (concerning certain benefits), are shown in table 9 (the percentage of respondents considering the web more effective (more benefits) than the compared media are indicated). In general, respondents rated the web as being more effective than the other media on the given criteria.

TABLE 9: THE EFFECTIVENESS OF THE WEB COMPARED TO DIFFERENT MEDIA

\begin{tabular}{|l|ccccc|}
\hline \multirow{2}{*}{ BENEFITS / EFECTIVENESS } & \multicolumn{4}{|c}{ EFFECTIVENESS OF WEB COMPARED TO OTHER MEDIA } \\
\cline { 2 - 6 } & $\begin{array}{c}\text { Web vs. } \\
\text { Printed media } \\
\%\end{array}$ & $\begin{array}{c}\text { Web vs. } \\
\text { Radio } \\
\%\end{array}$ & $\begin{array}{c}\text { Web vs. } \\
\text { Television } \\
\%\end{array}$ & $\begin{array}{c}\text { Web vs. } \\
\text { Billboards } \\
\%\end{array}$ & $\begin{array}{c}\text { Web vs. } \\
\text { Direct } \\
\text { advertising } \\
\%\end{array}$ \\
\hline Access to information of interest & 81.8 & 68.4 & 63.8 & 73.8 & 70.1 \\
Cost & 59.4 & 40.6 & 55.1 & 54.5 & 53.5 \\
Customer service & 43.3 & 58.8 & 48.1 & 61.0 & 56.7 \\
Availability of additional information & 75.4 & 74.3 & 74.3 & 74.9 & 72.7 \\
Entertainment & 35.8 & 29.4 & 18.2 & 51.9 & 51.3 \\
Global access to a company & 81.8 & 74.9 & 66.8 & 67.4 & 69.5 \\
Interaction with a company & 52.4 & 64.2 & 63.1 & 67.9 & 63.1 \\
Interaction with other people & 44.9 & 45.5 & 50.3 & 60.4 & 54.5 \\
Purchase convenience & 42.2 & 54.5 & 43.9 & 55.1 & 48.7 \\
Reach / exposure & 64.7 & 49.7 & 35.8 & 56.7 & 52.4 \\
Opportunity to be selective & 78.6 & 78.6 & 77.0 & 74.3 & 74.9 \\
Alternatives available & 57.8 & 65.8 & 60.4 & 64.7 & 62.0 \\
\hline
\end{tabular}

\section{RECOMMENDATIONS}

The challenge for any company that decides to make use of the web as a marketing tool is not just "getting connected" to the web. Rather, it is getting noticed and staying relevant. Although web usage could be seen as a common denominator, it doesn't mean that needs are alike. It varies from consumer to consumer. The web site must be designed with the consumer in mind. Companies must get to know their web markets just as well as they know their traditional markets. This will influence the way in which the consumer will experience the web site and form favourable perceptions of the web site. Ultimately, to be successful, web-based marketing must be an integrated part of a marketing plan. In other words, integrate the web online activities with offline marketing efforts to attract and enhance return visits to companies' web sites.

Web users (consumers) prefer dynamic content based sites and start to expect more and more of web sites. Where the web consisted of primary static content based sites only a few years ago, these sites are fast becoming something of the past. This is important for companies to pay attention to since the results showed that web sites must be dynamic, 
which means sites must be continually updated with new information. Consumers want to see changes on web sites that range from up-to-date content to new things. Therefore, sites must be developed in such a way that they will allow content to be updated in an easy and cost effective manner. Web sites should be developed by being database driven with a secure back-office functionality, which will allow company administrators to update content as and when required.

It is also suggested that companies should provide features that consumers must register for providing personal information in order to get to know the requirements of the target market on the web and produce features that best match and satisfy these markets. They can also provide functionality to consumers that will enable them to make suggestions on enhancements they want to see on a web site.

Companies must expose their URL's in as many ways and to as many consumers as possible, for example by means of business cards, letterheads, posters, and television. The more consumers are exposed to the URL's of web sites the greater the chances that they will attract consumers to web sites. Companies must also consider the media that they want to use in promoting their web sites - their selections should be based on the target market's preferences and opinions.

Concerning the aspects for further research, it is recommended that the different preferences and surfing habits based on the different profiles of the respondents be investigated to enable marketers to determine complete and proper bases or variables for web-market segmentation.

\section{BIBLIOGRAPHY}

ALLEN C. 1998. Apply one-to-one marketing techniques with personalization. [Online] Available from: http://allen.com.

ASPINAL G. 1997. Effective web marketing: what works and why. [Online] Available from: http://meep.com/magazine/biz.

BONNFIELD P. 2000. The evolutionary evolution. Intelligence, 6 (1): 16-18.

BRIGMAN L. 1996. Web site management excellence. Bergamo :QUE.

CARTON S. 2000. Brand is back. [Online] Available from: http://gt.clickz.com.

ELLSWORTH JH \& ELLSWORTH MV. 1995). Marketing on the Internet. New York: Wiley.

FRANKEL R. 1999. Adapting to the medium: how creativity is being used on the Internet. [Online] Available from: http://searchz.com/clickz.

GARRATT S. 1998. Buyer-seller romance to blossom in the net. Marketplace, 20 (9): 23. 
GIBSON K. 1999. Early days as e-commerce gets set for the big time. Netmaster Africa, 4 (4): 18-26.

GIBSON K. 1999. Marketing makes a difference. Netmaster Africa, 4 (2): 8-14.

GRAHAM I. 1997. HTML Sourcebook. Canada: Wiley.

HARDEN I, HEYMAN B \& SCHAEFER K. 1999. Marketing that works. [Online] Available from: http://pbs.mcp.com/ebooks.

HSU C. 2000. Business on the web: strategies and economics. [Online] Available from: http://viu.eng.rpi.edu/Persons.

KITCHING T. 1999. Four powerful rules to make your web site work. [Online]. Internet: http://www.tka.co.uk/magic/archive/archv12.htm\#Q2.

LANDMAN J. 2000. Everything a retailer needs to know about e-commerce, but is afraid to ask. [Online] Available from: http://jman5.com/e-tailer.

LING A. 2000. e.Bussiness is simply the way business will work in the future. Intelligence, 6(1): 10.

LIVERSAGE S. 2001. Online advertising's future. [Online] Available from: http://www.sa. internet.com/emarket/enews/00/11/04.htm.

MCNAMEE T. 1995. The Internet as a strategic marketing tool. [Online] Available from: http://resultsdirect.com/rd.

RICH GA. 2002. The Internet: Boom or Bust to Organisations? Journal of Marketing Management: 18, April.

SHEA V. 2001. Netiquette. [Online] Available from: http://www.albion.com/netiquette.

SCHMIDT E. 2000. Extending your business to the Internet is the solution. Intelligence, 6(1): 40-42.

WIESE L. 1999. The Internet: ignore it or embrace it? Marketplace, September, 21 (16): 44.

WILSON R. 1999. The web marketing checklist: 26 ways to promote your site. [Online] Available from: http://www.webmarketingtoday.com/articles/checklist.htm. 